\title{
UM OLHAR SOBRE AS CIÊNCIAS DA ENFERMAGEM: AS VERTENTES ANALÍTICAS DAS PRATICAS ASSISTENCIAIS
}

\author{
REVIEWING NURSING SCIENCE: AN INTRODUCTION TO REFLECTION
}

\section{UNA MIRADA SOBRE LAS CIENCIAS DE ENFERMERÍA: LAS VERTENTES ANALÍTICAS DE LAS PRACTICAS ASSISTENCIALES}

Emiko Yoshikawa Egry*

Egry EY. Um olhar sobre as ciências da enfermagem: as vertentes analíticas das práticas assistenciais. Rev Esc Enferm USP 2001; 35(3):265-70

\section{RESUMO}

Trata-se de um ensaio que traz à reflexão as vertentes de análise das práticas assistenciais através da compreensão das categorias de análise das investigações científicas no campo da saúde e da enfermagem, no contexto do ocaso do segundo milênio. Critica os marcos de análise utilizados na atualidade e sugere repensar os paradigmas na pesquisa e na prática de enfermagem.

PALAVRAS-CHAVE: Pesquisa. Enfermagem.

\begin{abstract}
This essay goals to present a reflection about issues of research and nursing practice in Brazil, in the context of the end of Second Millenium. It criticizes current and tradicional framework adopted in researches and practices. Finally it suggests the adoption of new paradigm in the researches and practices of nursing.
\end{abstract}

KEYWORDS: Research, Nursing.

\section{RESUMEN}

Trátase del ensayo que traze a la reflexión las vertientes del análisis de las prácticas assistenciales a través de la comprensión de las categorias del analisis de las investigaciones cientificas en el campo de la salud y de enfermeria, en el contexto del ocaso del segundo milênio. Critica a los marcos del análisis utilizados en la pesquisa y en la práctica de enfermería.

PALABRAS -CLAVE: Pesquisa. Enfermería.

- Enfermeira. Mestre em Enfermagem pela EEUSP. Doutor em Saúde Pública pela Faculdade de Saúde Pública da USP. Livredocente em Enfermagem em Saúde Coletiva da EEUSP. Professora Titular do Departamento de Enfermagem em Saúde Coletiva da EEUSP. Diretora da Escola de Enfermagem da Universidade de São Paulo. 


\section{INTRODUÇÃO}

A Enfermagem Moderna, instaurada no século passado por Nightingale, demandou várias e várias décadas para se constituir hoje enquanto campo - de conhecimentos e de práticas - reconhecido no meio científico. Mesmo que toda a prática humana seja revestida de intencionalidade, o que significa que há sempre um construto teórico em seu alicerce, nem sempre este foi de domínio ou consciência dos exercentes. Tal divisão entre o conhecer e o fazer se deu em sua própria origem, sob a égide do capitalismo, no qual no processo de trabalho há separação entre o aquele que pensa e aquele que faz. Despertada pela necessidade sócio-histórica das norte americanas, principalmente na década de 60 de nosso presente século, a pesquisa em enfermagem tomou vulto, no Brasil, na década de 70 , consubstanciada pela instauração dos programas de pós-graduação senso stricto. Earece que de lá para cá, decorridas quase três décadas a pesquisa em enfermagem no Brasil foi se adensando, respondendo aos desafios de melhor qualificar a prática - quer assistencial, quer de ensino, quer de gerenciamento - para selecionar apenas três grandes focos em que pesquisa está sendo desenvolvida. Olhar de perto as vertentes analiticas das práticas assistenciais é pensar os paradigmas que sustentam as pesquisas em enfermagem que por sua vez desvelam as práticas assistenciais.

Assim, é preciso ver a quantas andamos em termos de pesquisa científica na enfermagem e o quanto precisamos andar. Prova do grande fôlego das pesquisadoras enfermeiras (de propósito chamo a atenção ao gênero feminino por que constituímos a maioria dos exercentes) pode ser verificado através de: crescente demanda por apresentação em temas livres dos congressos brasileiros, regionais e temáticos; crescente demanda por financiamento junto às agências tais como a FAPESP e o CNPq, entre outras; aumento significativo de veículos ou títulos de divulgação científica da enfermagem; crescente aumento de demanda por publicações em revistas nacionais e internacionais, além da constituição de sociedades específicas dentro da enfermagem, sob o manto da Associação Brasileira de Enfermagem.

A despeito das criticas (procedentes, em determinados casos) de que nossas pesquisas apresentam maior volume nas que resultam em constatações e em descrições e pouco ainda daquelas que comprovam e validam dadas teorias de enfermagem, o Brasil já é de longe o maior produtor de pesquisas em enfermagem dentro da América Latina e dentro de nosso País, sem dúvida o Estado de São Paulo tem sido o maior produtor.

\section{Poderiamos com isso entrar no terceiro milênio com tranqüilidade?}

Felizmente para nós as pesquisadoras, não! Por que? Porque a própria produção científica - em todos os campos do conhecimento - se coloca hoje sub judice e as inquietações originam-se dos pesquisadores sociólogos, filósofos e demais cientistas, que estão debatendo, afinal que ciência é esta que produzimos?

\section{A PRODUÇÃO DO CONHECIMENTO SUB JUDICE}

Boaventura de Souza Santos, sociólogo, em seu livro "Um Discurso sobre as Ciências"w nos traz a grande questão em debate que torna a produção do conhecimento sub judice.

Ele pergunta, trazendo à tona uma questão antiga posta por Jean-Jacques Rousseau, em 1750, se há alguma relação entre a Ciência e a Virtude. De outro modo indaga se o progresso das ciências e das artes contribuirá para purificar ou para corromper os nossos costumes?

Como e quando superaremos o desvalor do conhecimento dito ordinário ou vulgar que criamos (nós os sujeitos individuais e coletivos) e usamos para dar sentido $\mathrm{s}$ nossas práticas e que a ciência teima em considerar irrelevante, ilusório e falso?

Qual é o papel de todo o conhecimento científico acumulado no enriquecimento ou no empobrecimento prático de nossas vidas, ou seja, pelo contributo positivo ou negativo da ciência para a nossa felicidade? Numa visão antecipatória do futuro das ciências, (1) traça as suas hipóteses: a) "a distinção entre as ciências naturais e ciências sociais deixa de fazer sentido; b) a síntese entre elas tem como pólo catalisador as ciências sociais; c) as ciências sociais terão que recusar todas as formas de positivismo lógico ou empírico ou de mecanicismo materialista ou idealista com a conseqüente revalorização do "humanidades" ou estudos humanísticos; d) a sintese não visa uma ciência unificada nem sequer uma teoria geral, mas um conjunto de galerias temáticas onde convergem linhas de água que até agora concebemos como objetos teóricos estanques; e) nessa medida, a distinção hierárquica entre conhecimento científico e conhecimento vulgar tenderá a desaparecer e a prática será o fazer e o dizer da filosofia da prática." 


\section{PARADIGMA OU QUESTÕES PARADIGMÁTICAS: O "INVISÍVEL" QUE CONFORMA A NOSSA PRATICA}

Todos os questionamentos anteriores, provocando a discussão em torno do conhecimento científico, direciona o olhar dos pesquisadores para as questões paradigmáticas ou mesmo os paradigmas que sustentam a compreensão dos fenômenos de investigação e como nos aproximamos para pesquisar. Com toda a certeza é possivel afirmar que a questão paradigmática norteia não somente nossa forma de aproximar de um campo de conhecimentos como também a nossa prática assistencial, queiramos ou não admitir a sua existência.

Kuhn nos ajuda a entender paradigmas, considerando que elas são "realizações científicas universalmente reconhecidas que, durante algum tempo, fornecem problemas e soluções modelares para uma comunidade de praticantes de uma ciência". Assim, a investigação (...) cuidadosa de uma determinada especialidade num determinado momento revela um conjunto de ilustrações recorrentes e quase padronizadas de diferentes teorias nas suas aplicações conceituais, instrumentais e na observação. Esses são os paradigmas da comunidade, revelados nos seus manuais, conferências e exercícios (...). Apesar das ambigüidades ocasionais, os paradigmas de uma comunidade científica amadurecida podem ser determinados com relativa facilidade. Contudo, a determinação de paradigmas compartilhados não coincide com a determinação das regras comuns ao

grupo "(2)

O pensamento de( $\left.{ }^{3}\right)$ sobre os paradigmas da pesquisa em educação, ilustram e servem de contraponto às pesquisas e às práticas em saúde, com toda certeza elas também podem espelhar e refletir a prática assistencial da enfermagem. A autora se reporta à obra de Egon Guba, The paradigm dialog, editado em 1990, como resultado da Conferência dos Paradigmas Alternativos, ocorrido em 1989, em São Francisco, Estados Unidos. O propósito da Conferência, de acordo com Guba, foi clarificar as alternativas que têm surgido "acrescentando que a intenção foi a de legitimar os contendores não hegemônicos, pela demonstração de que suas posições são, pelo menos, igualmente defensáveis e úteis".(3)

Assim, sob a compreensão do termo paradigma tomado como "um conjunto básico de crenças que orienta a ação - entendida como investigação disciplinada", são apresentados três paradigmas sucessores do positivismo: o pós-positivismo, a teoria crítica e o naturalismo/construtivismo. Ainda, a autora considera três dimensões para que se possa caracterizar cada um dos paradigmas: a dimensão ontológica [referente à natureza cognoscivel], a dimensão epistemológica [referente à relação conhecedor e conhecido] e a dimensão metodológica [como o conhecimento é construído pelo pesquisador] (3)

Em breves palavras - ou em síntese do que foi abordado por (3) - pode-se dizer a respeito de cada uma delas:

\section{Pós-positivismo}

Visão modificada do positivismo, cuja preocupação com a objetividade produzia o desequilíbrio entre: o rigor e a relevância (validade interna e externa); a precisão e a riqueza (por superenfatizar a quantificação); a elegância e a aplicabilidade (grounded theori como forma de resolver o impasse); entre o descobrimento e a verificação. Ontologicamente é crítico-realista, assumindo a existência de uma realidade externa ao sujeito; Epistemologicamente é objetivista-modificada, continuando a ser um ideal regulatório; metodologicamente é experimental/ manipulativa modificada.

\section{Teoria critica}

Investigação ideologicamente guiado, ou seja, a pesquisa é um ato político. O crítico tem dois sentidos: interno (questionamento analitico do argumento e do método) e externo, ou seja, das condições de regulação social, a desigualdade e o poder. Otologicamiente é critico-realista, está implícita a existência de uma verdadeira consciência e a crença em uma realidade objetiva que deve ser desvelada; Epistemologicamente é subjetivista, o processo de investigar é mediado pelos valores do pesquisador; Metodologicamente é dialógica, transformadora.

Naturalismo/ Construtivismo (a própria autora reconhece que não é o melhor termo)

Neste paradigma existem pré-concepções que o tornam incompativeis com os demais: o peso da teoria sobre os fatos, ou seja, os fatos somente existem no âmbito de um referencial teórico; existe uma subdeterminação da teoria, ou seja, nenhuma teoria pode ser totalmente testada; igualmente que os teórico-críticos, nenhuma investigação é neutra, o peso dos valores sobre os fatos e, sobretudo, existe uma natureza interativa entre o pesquisador e o pesquisado. Ontologicamente é relativista, as realidades existem sob forma de múltiplas construções mentais, fundadas nas experiências sociais de quem os formula; Epistemologicamente subjetivista - as realidades existem nas mentes dos sujeitos; Metodologicamente, 
hermenêutico-dialéticas, ou seja, as construções individuais são sempre provocadas e refinadas através da hermenêutica e controladas dialeticamente.

De acordo com Santos( ${ }^{(4)}$, estamos vivendo uma era e transição paradigmática, ou seja, a passagem entre paradigmas. "a partir de meados do século XIX, com a consolidação da convergência entre o paradigma da modernidade e o capitalismo, a tensão entre regulação e emancipação entrou num longo processo histórico de degradação caracterizado pela gradual e crescente transformação das energias emancipatórias em energias regulatórias. (...) Com o colapso da emancipação na regulação, o paradigma da modernidade deixa de poder renovar-se e entra em crise final. (...) Entre as ruinas que se escondem atrás das fachadas, podem pressentir-se os sinais, por enquanto vagos, da emergência de um novo paradigma."

A questão dos paradigmas se encontra, na atualidade, em pleno processo de revisão e elas também têm sido o objeto de estudos dentro da enfermagem. Verifica-se, por exemplo, que há uma pluralidade paradigmática no campo da saúde, e o que torna relativamente complicado é a pouca ênfase que os pesquisadores da saúde (e da enfermagem) têm dada a esta importante dimensão na aproximação dos fenômenos, tanto na pesquisa quanto na intervenção. $(5,6)$ Principalmente nas nossas práticas assistenciais os paradigmas nem entram na discussão, em geral porque os exercentes da enfermagem entendem que questões paradigmáticas são da ordem da "academia" ou da investigação e que nada dizem para fazem sentido para a assistência.

$\mathrm{Na}$ produção do conhecimento vive-se hoje a "transição paradigmática [que] implica a definição das lutas paradigmáticas, ou seja, das lutas que visam aprofundar a crise do paradigma dominante e acelerar a transição para o paradigma ou paradigmas emergentes. A transição paradigmática é um objetivo de muito longo prazo.(4)

Para nós da saúde, assim como na educação, é possivel verificar a coexistência destes paradigmas que sustentam a produção de conhecimentos, bem como a nossa prática assistencial, de ensino, de gestão, entre tantas outras. Devemos acompanhar o debate acerca da possibilidade de acomodação entre os paradigmas ou sua impossibilidade, defendida por diferentes autores. Importa também considerar que o clareamento da questão paradigmática nos remete ao aprofundamento dos marcos teórico-filosóficos que embasam nossa prática (de investigação e de ação) e ao minimo buscar bases sólidas - epistemológicas e metodológicas - de abordagem dos objetos de investigação, resultando em produtos, com coerência em termos ontológicos, epistemológicos e metodo- lógicos. Não nos cabe, no presente momento (e em momento algum) dizer qual deles é mais verdadeiro, mesmo porque não existe esta verdade única na ciência e, porque não existe, a discussão dos paradigmas faz sentido. Cabe, no entanto, estancar as discussões infrutiferas de oposição (falsa) entre quantitativo $x$ qualitativo e objetivo $x$ subjetivo.

O paradigma dominante cartesiano está em crise, pelo seu próprio desenvolvimento: o aprofundamento do conhecimento permitiu ver as fragilidades dos pilares em que se funda - a quantificação, a redução da complexidade - pois conhecer [no paradigma cartesiano] significa dividir e classificar para depois poder determinar as relações sistemáticas entre o que se separou. "Depois da euforia científica do século XIX e da conseqüente aversão à reflexão filosófica, bem simbolizada pelo positivismo, chegamos ao final do século XX possuídos pelo desejo quase desesperado de complementarmos os conhecimentos das coisas com o conhecimento do conhecimento das coisas, isto é, com o conhecimento de nós próprios". (1)

Os paradigmas emergentes estão buscando assentar mais nas chamadas pesquisas qualitativas, ao verificar principalmente que o positivismo esbarrou nos limites dos quais as ciências que se ocupam dos fenômenos complexos estão mais atinentes. $\mathrm{Na}$ enfermagem ocorre este movimento. Cabe, portanto decifrar ...

\section{O que é qualidade?}

Num estudo recente, (7), a propósito de elucidar a pesquisa qualitativa, traz importantes considerações acerca da definição da qualidade. Apelando para o sentido etimológico, qualitas, em latim, significa a essência, diz o autor. "Assim, qualidade designa a parte essencial das coisas, aquilo que lhe seria mais importante e determinante (...) a qualidade aponta para a marca central das coisas e dos seres, aquilo que não se consome no tempo, que fica para sempre, que decide o que algo é definitivamente".

Além disso, a qualidade "aponta para a perfeição historicamente possivel sobretudo do ser humano ou da história. Nesta maneira de ver, já abandonamos a aplicação do conceito a tudo, reservando-o para o fenômeno histórico, e sobretudo ao fenômeno humano. Ao mesmo tempo, não sendo perfeição apenas algo dado, mas principalmente construído na história, trata-se de apanhar aqueles fenômenos que representariam conquistas históricas consideradas desejáveis ou que expressam realização humana relevante". Continuando o debate, o autor considera que por não haver perfeição na história, imediatamente a qualidade remete à utopia e na 
história concreta, a participação representaria esta utopia. Em terceiro plano, "a qualidade sinaliza o horizonte da intensidade, para além da extensão." A intensidade está dialeticamente disposta à extensão, a primeira apontando para a dimensão do melhor e a segunda para o maior. Ademais a intensidade denota dimensões tais como: "a) fenômenos que não se esgotam no superficial, mas marcam-se pela profundidade, como o amor; b) fenômenos que reagem à rotina extensa e, por isso, buscam renovar-se sempre, como a felicidade; c) fenômenos que primam pela dinâmica do compromisso, como é o engajamento politico, ou a militância; d) fenômenos que indicam a plenitude da realização humana, como é a santidade; e) fenômenos que valorizam participação humana, mais que a mera presença física ou quantitativa, como é o envolvimento comunitário, a democracia, a cidadania; f) fenômenos que apontam para dimensões valorativas do ser humano, como a dedicação, a ética, a abnegação, o envolvimento, a prestatividade, a solidariedade, etc" (7).

Entretanto, há uma inseparável unidade entre quantidade e qualidade. De acordo com as Leis da Dialética, reportando-se principalmente à segunda Lei, "todos os fenômenos têm características que se determinam quantitativamente e propriedades decorrentes do conjunto dessas características que revelam o seu caráter qualitativo (qualidade como sendo propriedade essencial do sistema material). Todos os sistemas materiais também possuem determinações quantitativas (grandeza, volume, peso, intensidade e ordenação estrutural) e, assim, a qualidade existe sempre em inseparável unidade com a quantidade. As transformações existem primeiro na quantidade (evolução) e preparam-se para as transformações qualitativas (salto qualitativo) ${ }^{(8)}$.

Por outra, diz (1), "não faz sentido apostar na dicotomia entre quantidade e qualidade, pela razão simples de que não é real. Pode-se no máximo, priorizar uma ou outra, por qualquer motivo, mas nunca para insinuar que uma se faria às expensas da outra, ou contra a outra. Todo fenômeno qualitativo, pelo fato de ser histórico, existe em contexto material, temporal, espacial. E todo fenômeno histórico quantitativo, se envolver o ser humano, também contém a dimensão qualitativa. Assim, o reino da pura quantidade ou da pura qualidade é ficção conceitual."

Assim, em termos de um Objeto novo que se compõe na prática assistencial (o coletivo) é necessário pensar uma perspectiva histórica na metodologia de pesquisa que se aproxime de nosso objeto de investigação, é, pois pensar "o método enquanto um elemento constitutivo da intervenção da enfermagem [em saúde coletiva], é um instrumento (saber, técnica

e procedimento) a ser utilizado no processo de trabalho, cuja finalidade genérica é a transformação da realidade de saúde e doença da coletividade. Parte integrante do processo de trabalho da enfermagem, por sua vez, inscrito num processo de trabalho maior, o da produção de serviços em saúde, o método não pode ser separado enquanto uma entidade abstrata e fora dessa realidade, sem o que arrisca-se a perder seu caráter instrumental" (5)

A investigação na perspectiva histórica é um processo de trabalho cuja finalidade é a geração do conhecimento na saúde (enfermagem): ela mesma é um fenômeno social articulado ao trabalho da saúde, por sua vez uma prática social, desenvolvida numa realidade concreta e histórica. Hoje, é possivel afirmar que a adoção de um método que separa instrumento e objeto de investigação coloca em risco o seu caráter instrumental além de desvestir o objeto de estudo da historicidade e da socialidade que lhe são peculiares.

$\mathrm{Na}$ sua vertente metodológica, a Teoria de Intervenção Práxica em Enfermagem em Saúde Coletiva, uma das possibilidades metodológicas da perspectiva histórica, "é a sistematização dinâmica de captar e interpretar um fenômeno articulado aos processos de produção e reprodução social referentes à saúde e doença de uma dada coletividade, no marco da sua conjuntura e estrutura, dentro de um contexto social historicamente determinado; de intervir nessa realidade e, nessa intervenção, prosseguir reinterpretando a realidade para novamente nela interpor instrumentos de intervenção" (5)

No trabalho da enfermagem há ainda um outro aspecto a ressaltar: o fato de tratar-se de uma profissão eminentemente feminina que se caracteriza por uma prática historicamente vinculada à função social da mulher - o cuidar, o que a submete a uma dupla subordinação - social, ao trabalho médico, e de gênero, ao masculino (9).

Assim sendo, além dos inúmeros desafios colocados pela área da saúde na defesa intransigente da eqüidade, cabe à enfermagem redefinir sua prática assistencial e de ensino, na luta pela transformação da sua subalternidade social (10). Para tanto, cumpre transformar os conteúdos e os métodos de qualificação da força de trabalho em Enfermagem, incluindo as necessárias reflexões sobre as especificidades do trabalho de cada categoria funcional, com ênfase na situação da mulher.

\section{CONCLUSÃo}

As Questões Epistemológicas referidas por ${ }^{(11)}$, os debates de $\left(1,7^{12}{ }^{21}\right.$, acrescidos das que retratamos em 
obras anteriores $(5,6,13,14)$, trazem para dentro do campo da enfermagem, importantes interrogantes para prosseguirmos a discussão acerca de nossa prática assistencial e das suas vertentes inspiradoras:

- Quanto da nossa ciência de enfermagem que trata mediata ou imediatamente do humano é mesmo humanizado - considerando sua complexidade de viver o processo saúde-doença?

- Como o produtor do conhecimento (pesquisador) se auto-verifica enquanto parte da totalidade de produção dos serviços de saúde, ou seja, ele mesmo com potencialidades e desgastes decorrentes de sua forma de inserção no trabalho?

- $\quad$ As pesquisas em enfermagem informam [mais] para o instituido ou [mais] para o instituinte? Elas informam para uma atenção solidária, participativa, ou mantenedora da desigualdade de poder através do saber?

- Conformar-se (dar conformidade) aos projetos para atender às possibilidades das agências de fomento ou a determinados grupos instituidos é uma estratégia para a produção de um conhecimento emancipador (da profissão e das profissionais, assim como dos usuários) ou tem sido um fim em si mesmo?

O terceiro milênio abre as portas para nós da enfermagem consolidarmos a autonomia (que quero que entendam num processo coletivo de trabalho em saúde), enquanto uma categoria da liberdade, e para que essa autonomia seja legítima (e não meramente legal, como por exemplo no estatuto das ciências) necessitamos resgatar as nossas potencialidades que foram adormecidas ao longo de nossa passagem pela era cartesiana. Em outras palavras, significa recuperar nosso modo científico (no novo paradigma) de humanizar através de conhecimentos e de atos cuidativos com o que parece estar sendo confluente com o nosso ser feminino histórico e socialmente construído..

\section{REFERENCIAS BIBLIOGRÁFICAS}

(1) Santos BS. Um discurso sobre as ciências. 9 a ed. Porto: Afrontamento; 1997

(2) uhn TS. A estrutura das revoluções cientificas. 3g ed. São Paulo: Perspectiva; 1995.

(3) Mazzotti AJA. O debate atual sobre os paradigmas de pesquisa em educação. Cad Pesq SP 1996; (96): 15-23.

(4) Santos BS. A crítica da razão indolente: contra o desperdício da experiência. São Paulo: Cortez; 2000.

(5) Egry EY. Saúde coletiva: construindo um novo método em enfermagem. São Paulo: İcone; 1996.

(6) Egry EY. Enfermagem em saúde coletiva: das categorias de análise / intervenção. São Paulo: Escola de Enfermagem da USP; 1998. (mimeografado).

(7) Demo P. Pesquisa qualitativa. Busca de equilíbrio entre forma conteúdo. Rev Lat Am Enferm 1998; 6(2): 89-104.

Cheptulin A, A dialética materialista: categorias e leis da dialética. São Paulo: Alfa-omega; 1982.

Fonseca TMG. De mulher a enfermeira: conjugando trabalho gênero. In: Lopes MJ, Meyer DE, Waldow VR, organizadores. Porto Alegre: Artes Médicas; 1996. p.62-75.

(10) Fonseca RMGS. Mulheres e enfermagem: uma construção generificada do saber. [tese] São Paulo(SP): Escola de Enfermagem da USP; 1996.

(11) Japiassu H. Questões epistemológicas. Rio de Janeiro: Imago; 1981.

(12) Minayo MCS. O desafio do conhecimento: pesquisa qualitativa em saúde. $4^{a}$ ed. São Paulo: Hucitec / Abrasco; 1996.

(13) Antunes MJM, Silva IA, Egry EY, Sena RR, Almeida MCP. Manual do pesquisador: orientação para o trabalho de campo. Brasília: ABEn; 1997.

(14) Egry EY. Pesquisar para evoluir? Pesquisar para superar! Rev Esc Enferm USP 1992; 26 (nesp): 141-51.

Artigo recebido em 21/09/99

Artigo aprovado em 11104102 